\title{
Transmissibility of Mycoplasma Dispar under Experimental Conditions
}

\author{
By $R$. Tanskanen
}

\begin{abstract}
Tanskanen R.: Transmissibility of Mycoplasma dispar under experimental conditions. Acta vet. scand. 1987, 28, 227-240. - Twenty three 1- to 18-week old Ayrshire calves were exposed to infection by Mycoplasma dispar, 1 or 2 at a time, in a series of consecutive experiments. Exposure took place either at direct contact, i. e. with the possibility of physical contact between susceptible and infected calves (type I), or through separation of susceptibles from the nearest infected calf at a distance of $0.8 \mathrm{~m}$ (type II) or $1.3 \mathrm{~m}$ (type III). Frequent nasal swabbing was used for the detection of the infection and the measurement of the level of colonisation.

Ten, 4 , and 9 calves were subjected to type I, II, and III exposures, respectively. When the first positive nasal specimen preceding a rise in titres in the following specimens was used to signify an establishment of infection of a susceptible calf, the medians (ranges) of the times for the transmission of infection (including the latent period of early colonisation undetectable by nasal swabbing) in the 3 exposure groups were: $4.5(1-27), 8.5(7-9)$, and $17(6-32)$, respectively. The difference between groups I and III was significant $(p<0.05)$. The last figures for type III of exposures represent the results of only 5 calves succesfully exposed; the remaining 4 of the 9 calves of this exposure type were not found to pick up the infection within the periods of 2 to 3 weeks of exposure. The results indicate a transmission mode via droplets.

Four calves exposed only for $4 \mathrm{~h}$ by direct contact were found to be infected on days $0,4,4$, and 7 , respectively. This indicated variability in the length of the latency as regards the detection by nasal swabbing.

Four of the 7 calves in the type I experiments sampled at hour 4 showed low titers for M. dispar. Only in 1 of these calves was this early finding of transfer followed by positivity and a rise in titers through subsequent specimens. The other 3 calves became positive anew, with subsequent developing colonisation, first on days 4,4 , and 12 , respectively.
\end{abstract}

Mycoplasma infections; mycoplasmosis in cattle; respiratory diseases of cattle; epidemiology; disease transmission.

\section{Introduction}

Mycoplasma dispar appears to be a common inhabitant of both the healthy and diseased respiratory tract of calves (Gourlay et al. 1970, Thomas \& Smith 1972, Bitsch et al. 1976, Munster et al. 1979, Tanskanen 1987a). The potential pathogenicity of $M$. dispar has been established by experiments in gnotobiotic calves (Howard et al. 1976, Gourlay et al. 1979), by inoculations into 
the bovine mammary gland (Brownlie et al. 1976 ), in vitro by experiments on tracheal organ cultures (Thomas \& Howard 1974) and more recently also by epidemiological evidence (Rosendal \& Martin 1986, Tanskanen 1987a). Experimental studies (Tanskanen 1984) have demonstrated that $M$. dispar, when allowed to infect young calves naturally, effectively and extensively colonised their respiratory tract. The colonisation was not only restricted to the upper parts of the respiratory tract but also involved the tracheobronchial tree. After the initial discovery of infection using nasal swabbing the nasal titers increased within 5 to 12 days to the level of $10^{5}$ colour changing units (ccu) or higher; they remained at that level for a period of 2 to 5 months and then gradually decreased. It was further demonstrated that as regards the earlier phase of colonisation, the method of nasal swabbing was a reliable way of detecting the infection; in the later phases false negative results were often obtained.

The findings suggest that this kind of highdegree and long-standing colonisation with abundant shedding of organisms probably serves as a relatively effective source of infection for susceptible calves. No experimental or detailed epidemiological data, however, have so far been reported on the transmissibility of this agent. The present study was conducted to clarify some basic characteristics of the transmissibility of M. dispar under experimental conditions.

\section{Materials and methods \\ Calves}

Twenty three conventionally reared, 1 - to 18-week old Ayrshire calves (nos. 1-23) served as susceptibles in the experiments. The first 8 calves (nos. 1-8) have been described in the colonisation study previously reported
(Tanskanen 1984). Nine of the remaining calves (nos. 9, 13, 16-19, 21-23) originated from 2 of the other Departments of the Helsinki College of Veterinary Medicine. Six calves (nos. 10-12, 14, 15, 20) were purchased from 4 small dairy farms located in the north-east Uusimaa. The native farms of the calves to be used were found to be free of infection by $\mathrm{M}$. dispar by repeated testing. The transport of the calves to the experimental facilities was conducted under isolated conditions. Before exposure each calf was kept in isolation for approximately 1 month's time and tested 2 to 9 times to secure freedom from infection by $\mathrm{M}$. dispar. Three calves (nos. 11, 12 and 15) were found to harbour a mild M. bovirhinis infection before being subjected to the experiments.

Three 9- to 10-months old calves (nos. 122-124), used earlier in the initial colonisation study by the author (Tanskanen 1983), and two 2- to 3-month old calves (nos. 128 and 129) having been infected through calves nos. 122-124 were used as the source of infection for the first susceptible calf (no. 1). In later experiments, conducted in series, the susceptible calf or calves of one experiment having caught the infection were in turn used in the next experiment, as the source of infection, to a new susceptible or susceptibles. Additionally, one 3-month old calf (no. 145) acquired from one of the Departments of the College was inoculated with $\mathrm{M}$. dispar and used as a source of infection for the series of experiments of 3 susceptible calves (nos. 9-11). The origin of calves nos. 122-124 has been described earlier (Tanskanen 1983). Calves nos. 128 and 129 originated from 2 local dairy farms. No mycoplasmas could be isolated from the nasal passages of these latter 2 calves and calf no. 145 when sampled before their arrival to the facilities. 




Figure 1. The floor plan and location of pens in the animal room (I) and the operation room (II) of the isolation unit. The enclosure (A) divided by fences in 2 or 3 common pens; individual pens (B) by solid walls. The place of inlet $(\uparrow)$, in the wall at a level of $2.4 \mathrm{~m}$ and ridge outlet ( ) are shown.

\section{Experimental facilities}

The experiments were carried out in 2 isolation units located in a separate building, specially designed for experimental studies of infectious diseases. Each isolation unit contained an animal room $\left(83 \mathrm{~m}^{3}\right.$ in size) and an animal handling room $\left(37 \mathrm{~m}^{3}\right.$ in size). Each animal room contained a main enclosure divided by fences into 2 or 3 pens (Fig. 1). The fences allowed direct contact between calves in adjacent pens. Additionally, separate individual pens with solid walls of $1.0 \mathrm{~m}$ in height were located in both rooms when required. Up to 5 calves could simultaneously be housed in the 3 pens of the main enclosure. Straw was used for bed- ding. The pens were cleaned daily and new straw was supplied.

Air-conditioning (input and output) was controlled by electrical fans with 2 different speeds. The lower speed ( 8 air changes per hour) was normally in use in the wintertime and the higher one (16 air changes per hour) in the summertime. Air movement at calf height was about 0.15 or $0.30 \mathrm{~m} / \mathrm{sec}$, respectively, according to the 2 speeds of the fans. In order to prevent infectious agents from escaping from the building, the conditions of negative atmospheric pressure were set. In the wintertime the air blown into the rooms was heated to $18^{\circ} \mathrm{C}$. Some supplementary heating was also in use in the wintertime. During the colder half of the year (from November to April) the mean daily maximum and minimum temperatures and variations (S.D.) were 17.1 (1.3) and 15.7 $(1.1)^{\circ} \mathrm{C}$, respectively. Relative humidity varied from 17 to $81 \%$ with a mean of $41.2 \%$. In the warmer half of the year (from May to October) the respective temperature values were $20.7(1.9)$ and $18.7(1.4)^{\circ} \mathrm{C}$; relative humidity varied from 33 to $80 \%$ with a mean of $58.7 \%$ during those months.

\section{Arrangements of experiments}

The experiments were carried out in 1982-1984. Susceptible calves, 1 or 2 at a time, were in most cases exposed to natural infection by M. dispar according to 1 of 3 different schemes, for which the basic positional relations between calves are described in Figs. 1 and 2. A susceptible calf was either placed in the direct contact (allowance of physical contact) with the infected calves (Exposure type I) or it was exposed at a pen distance of $0.8 \mathrm{~m}$ (Exposure type II) or 1.3 $\mathrm{m}$ (Exposure type III) to the nearest infected calf. Practically, in type I exposure the infected calves were placed in the same and/or adjacent pen with the susceptible calf. The 

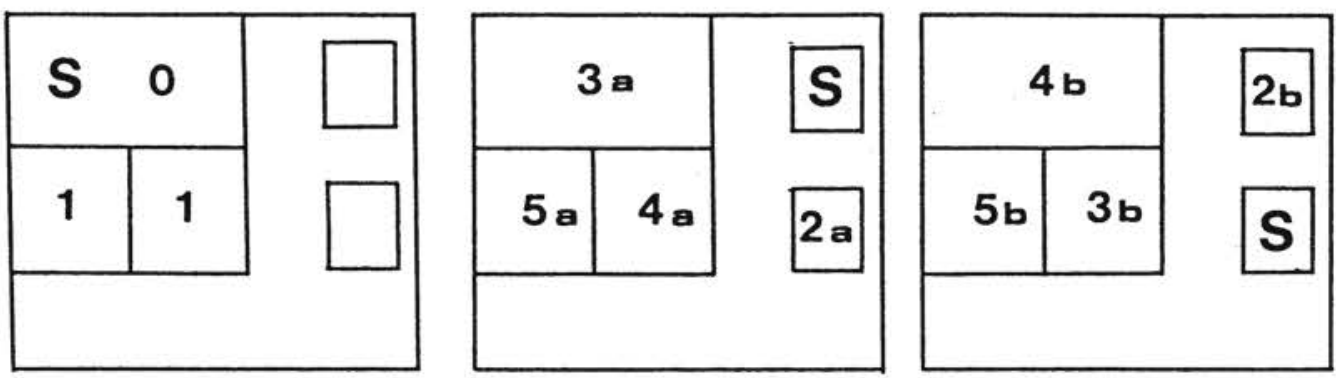

Figure 2. Alternatives of the positions of infected calves $(0-5)$ with respect to a susceptible ones $(\mathrm{S})$ in an animal room.

susceptible calf was either transferred after an exposure period of $4 \mathrm{~h}$ to a separate individual pen in the animal handling room or, more commonly, the exposure was allowed to continue throughout the experiment. In type II and III exposures, with susceptibles in a separate individual pen, additional infected calves were regularly placed at a further or further distances from the susceptible calf. If a susceptible calf after 2 to 5 weeks of exposure of type III was still found free from M. dispar it was exposed anew through closer contact with the same infected calves.

As a type of initial experiment, 7 of the susceptible calves (nos 13, 16, 17, 20-23) were placed in the animal handling room, adjacent to the animal room housing the infected calves for a period of a fortnight to investigate the possibility of transmission of $\mathbf{M}$. dispar from one room to another in the prevailing conditions of the experiments. The door between the rooms was kept closed when not used. The susceptible calves, which did not catch the infection during this initial experiments, were later exposed in the animal room according to the schemes described above.

In all experiments transmission of infection by non-intended means, such as through the hands or clothes of persons handling the an- imals or through utensils, was meticulously avoided. Persons handling the animals and taking the specimens were strictly instructed always to operate in the fixed order: first the susceptible calves, then the infected ones. Hands were cleaned and protective clothing was changed between the handling of the susceptible and infected calves.

\section{Sampling}

The techniques of obtaining nasal and transtracheal specimens as well as sampling frequencies for the first 8 calves have been described previously (Tanskanen 1984). In later experiments nasal sampling frequencies for susceptible calves varied according to the type of exposure. In case of exposure type I, most of the susceptible calves were sampled daily for the first 10 days, then all the calves twice a week for the period of the following 3 weeks and thereafter once a week. Some calves (nos. 11, 13, 15-17, 20, 21) were also sampled $4 \mathrm{~h}$ after the start of the exposure. In exposure types II and III the susceptible calves were sampled twice a week. Infected calves, when acting as source of infection, were sampled twice a week, otherwise weekly specimens were taken. All nasal specimens were taken as duplicates. Occasional transtracheal aspiration specimens were also taken. 


\section{Strain used}

The origin and identification of the strain of M. dispar used in its uncloned form in exposures of the first 8 calves have been previously described (Tanskanen 1983). The source of infection for calf no. 9 was calf no. 145 , which had been inoculated with a twice cloned strain of M. dispar isolated from calf no. 2. All 15 calves belonging to the latter part of the experiments were exposed to infection by this purified strain of M. dispar.

\section{Culture and identification of mycoplasma}

The medium used throughout the study was the glucose calf-serum (GS) broth described by Gourlay \& Leach (1970) and modified as previously described (Tanskanen 1984). Occasionally, in parallel with GS-broth a conventional mycoplasma medium of the Hayflick's type or a selective GS-broth with added antiserum to $M$. bovirhinis was used in culturing specimens. All these media were prepared as previously described (Tanskanen 1984). Culturing and identification methods used have been also described previously (Tanskanen 1984).

\section{Clinical observations of calves}

The calves were clinically monitored as described previously (Tanskanen 1984).

\section{Results}

Tables 1, 3 and 4 indicate the schemes and results of the experiments of the 3 exposure types by individual calves, with some results of clinical observations on the calves also included. Because of some uncertainity as to the source of infection the results of the new exposures of the 4 calves, which remained negative in exposure type III, are not included in these 3 tables but will be separately presented in the text.

Table 1 shows the results of 10 calves exposed through direct contact with infected calves. Table 2 shows their titers of M. dispar in nasal and transtracheal specimens intermittently taken during the 3 weeks subsequent to the first detection of the agent. For 4 of these 10 calves the time of exposure was only $4 \mathrm{~h}$. All these 4 calves acquired the infection through this exposure; the time of first detection of the agent varied from $4 \mathrm{~h}$ to 7 days. In calf no. 20 the first nasal specimen, taken at $4 \mathrm{~h}$ after the start of exposure, showed a low titer and the titers gradually increased during the following days, whereas in calf no. 17 , also positive at hour 4 , negative specimens were subsequently interposed and the calf became anew positive only on day 4, after which an increase in titers was recorded. From calves nos. 11 and 22, also exposed only for $4 \mathrm{~h}$, the first detection of M. dispar was made on days 7 and 4, respectively. Six out of the 10 susceptible calves exposed through direct contact were allowed to stay with the infected calves even after they were found to be themselves infected. In 5 of them M. dispar was detected within the first week of exposure, whereas from one (calf no. 15) M. dispar was not isolated earlier than on day 27. The somewhat lower than average titers in the calves acting as sources to calf no. 15 were observed, although they may not have been significant. The titer of $10^{6} \mathrm{ccu}$ in $0.2 \mathrm{ml}$ of the transtracheal aspiration specimen taken on day 27 indicated that the colonisation of $\mathbf{M}$. dispar then, however, involved the lower parts of the respiratory tract as well and to a definitely higher titer. Nasal specimens from calf no. 21 , positive with low titer $4 \mathrm{~h}$ after the start of the exposure, were for a second time positive first on day 12 , whereafter a gradual increase in titer levels took place.

Table 3 presents the results of type II exposures of 4 calves. They were all found to be infected on days 7 to 9 , whereafter their subsequent nasal specimens were regularly positive. 
Table 1. Exposure of 10 susceptible calves through direct contact with calves infected by M. dispar. Either exposure time was $4 \mathrm{~h}$ (Exposure type IA) or the susceptible calves were allowed to stay with infected calves throughout the experiment (Exposure type IB).

\begin{tabular}{|c|c|c|c|c|c|c|c|c|}
\hline \multirow{2}{*}{\multicolumn{2}{|c|}{ Susceptible calf }} & \multicolumn{6}{|c|}{ Conditions of exposure } & \multirow[b]{3}{*}{$\begin{array}{l}\text { Day of the first positive } \\
\text { (and the last negative) } \\
\text { nasal specimen from the } \\
\text { exposed calfe. }\end{array}$} \\
\hline & & \multirow[b]{2}{*}{ Type } & \multicolumn{5}{|c|}{ Infected calves } & \\
\hline No & $\begin{array}{l}\text { Age at the } \\
\text { start of the } \\
\text { exposure } \\
\text { (days) }\end{array}$ & & No & $\begin{array}{l}\text { Posi- } \\
\text { tion* }\end{array}$ & $\begin{array}{l}\text { Mean titer (S.D.) } \\
\text { for M. dispar } \\
\text { during the } \\
\text { exposure }\end{array}$ & $\begin{array}{l}\text { Days infected } \\
\text { before the } \\
\text { experiment }\end{array}$ & $\begin{array}{l}\text { Clinical } \\
\text { signs** }\end{array}$ & \\
\hline 11 & 113 & IA & $\begin{array}{r}10 \\
145 \\
9\end{array}$ & $\begin{array}{l}0 \\
1 \\
1\end{array}$ & $\begin{array}{l}7.0(0.0) \\
2.0(0.0) \\
3.0(0.0)\end{array}$ & $\begin{array}{r}35 \\
140 \\
123\end{array}$ & $\begin{array}{l}+ \\
- \\
-\end{array}$ & $7(4)$ \\
\hline 17 & 67 & IA & $\begin{array}{l}13 \\
16\end{array}$ & $\begin{array}{l}0 \\
1\end{array}$ & $\begin{array}{l}7.0(0.0) \\
7.5(0.7)\end{array}$ & $\begin{array}{l}35 \\
21\end{array}$ & $\begin{array}{l}- \\
+\end{array}$ & $0 / 4 h^{* * * * *}$ \\
\hline 20 & 34 & IA & $\begin{array}{l}13 \\
16 \\
17\end{array}$ & $\begin{array}{l}0 \\
0 \\
1\end{array}$ & $\begin{array}{l}6.4(0.9) \\
6.2(1.1) \\
7.4(0.5)\end{array}$ & $\begin{array}{r}127 \\
113 \\
92\end{array}$ & $\begin{array}{l}+ \\
+ \\
-\end{array}$ & 0 \\
\hline 22 & 39 & IA & $\begin{array}{l}21 \\
20 \\
13\end{array}$ & $\begin{array}{l}0 \\
1 \\
1\end{array}$ & $\begin{array}{l}7.0(0.0) \\
5.5(0.0) \\
5.0(0.0)\end{array}$ & $\begin{array}{r}15 \\
104 \\
231\end{array}$ & $\begin{array}{l}- \\
+ \\
-\end{array}$ & $4(3)$ \\
\hline 12 & 116 & IB & 11 & 0 & $4.3(3.1)$ & 0 & - & $7(3)$ \\
\hline 13 & 26 & IB & $\begin{array}{l}11 \\
12\end{array}$ & $\begin{array}{l}0 \\
1\end{array}$ & $\begin{array}{l}4.0(0.0) \\
8.0(1.4)\end{array}$ & $\begin{array}{l}45 \\
37\end{array}$ & $\begin{array}{l}H \\
H\end{array}$ & $5(4)$ \\
\hline 14 & 65 & IB & $\begin{array}{l}12 \\
13 \\
11\end{array}$ & $\begin{array}{l}0 \\
1 \\
1\end{array}$ & $\begin{array}{l}5.0(0.0) \\
6.5(0.7) \\
3.0(0.0)\end{array}$ & $\begin{array}{l}43 \\
15 \\
50\end{array}$ & $\begin{array}{l}+ \\
- \\
+\end{array}$ & $1(0)$ \\
\hline 15 & 84 & IB & $\begin{array}{l}11 \\
14 \\
12\end{array}$ & $\begin{array}{l}0 \\
1 \\
1\end{array}$ & $\begin{array}{l}3.1(0.4) \\
1.6(1.5) \\
3.7(0.7)\end{array}$ & $\begin{array}{c}64 \\
6 \\
57\end{array}$ & $\begin{array}{l}- \\
+ \\
+\end{array}$ & $27(20)$ \\
\hline 16 & 30 & IB & $\begin{array}{l}13 \\
10\end{array}$ & $\begin{array}{l}0 \\
1\end{array}$ & $\begin{array}{l}4.5(0.7) \\
1.6(1.1)\end{array}$ & $\begin{array}{r}16 \\
106\end{array}$ & $\bar{H}$ & $0 / 4 h^{* * * *}$ \\
\hline 21 & 22 & IB & $\begin{array}{l}20 \\
13\end{array}$ & $\begin{array}{l}1 \\
1\end{array}$ & $\begin{array}{l}6.2(0.0) \\
3.0(0.0)\end{array}$ & $\begin{array}{r}77 \\
204\end{array}$ & - & $0 / 4 h^{* * * *}$ \\
\hline
\end{tabular}

* The infected calf stayed in the same pen as $(0)$ or in a pen adjacent that of the susceptible one (1) in the main enclosure (see Fig. 1 and 2).

** Clinical signs during the exposure time are coded as follows: no signs of clinical illness (-); shorter or longer episodes of mild respiratory illness with occasional coughing and slight temperature rises (+); a more severe respiratory illness with frequent coughing and pyrexia (++).

*** The specimens on day 0 were taken 4 hours after the start of exposure.

***** The days starting the pattern of increase in nasal titers for calves nos. 17,16 and 21 were 4,4 and 12 , respectively (see Table 4). 
Five out of the 9 calves exposed by type III were found to be infected on days 6 to 32 (Table 4). Four calves (nos. 1, 2, 3 and 19 remained negative throughout the exposure periods of 13 to 23 days. They were thereafter exposed through a closer type of arrangement to the same infected calves. Calf. no. 1 was transferred to the same pen as calves nos. 128 and 129 and found to be infected on day 2 after the start of this new exposure with the nasal titer as high as $10^{5} \mathrm{ccu}$. Calf no. 2 was placed in the same pen as calves nos. 1, 128 and 129 and it was found to be infected not earlier than on day 19 after the start of this new exposure; the last negative specimen was taken on day 16. Calf no. 3 escaped from its pen in the night between days 16 and 17 of type III exposure and the specimen taken on day 17 showed a low titer of $10^{3} \mathrm{ccu}$ for M. dispar. Calves nos. 18 and 19 were simultaneously submitted to type III exposure. The distance between their pens was $1.1 \mathrm{~m}$ (see Fig. 1). Calf no. 18 was first found to be positive on day 19. Calf no. 19 , allowed to remain in the above mentioned exposure situation for a longer time, was found to be infected no earlier than on day 39 of the exposure. The next nasal specimens taken after the first detection of M. dispar in all these 9 calves exposed solely or primarily through type III exposure were positive.

Fig. 3 summarizes the results of the main exposures of all 23 susceptible calves grouped according to the 3 types of exposure. For the sake of better comparability between the results of the 3 types of exposure, in the group of the type I exposures the first findings of M. dispar in calves nos. 17, 16 and 21 that were not followed by regular and rising titers in subsequent specimens, were not taken into account. As an indication of successful infection in these calves only the first titer preceding such a regular appe-

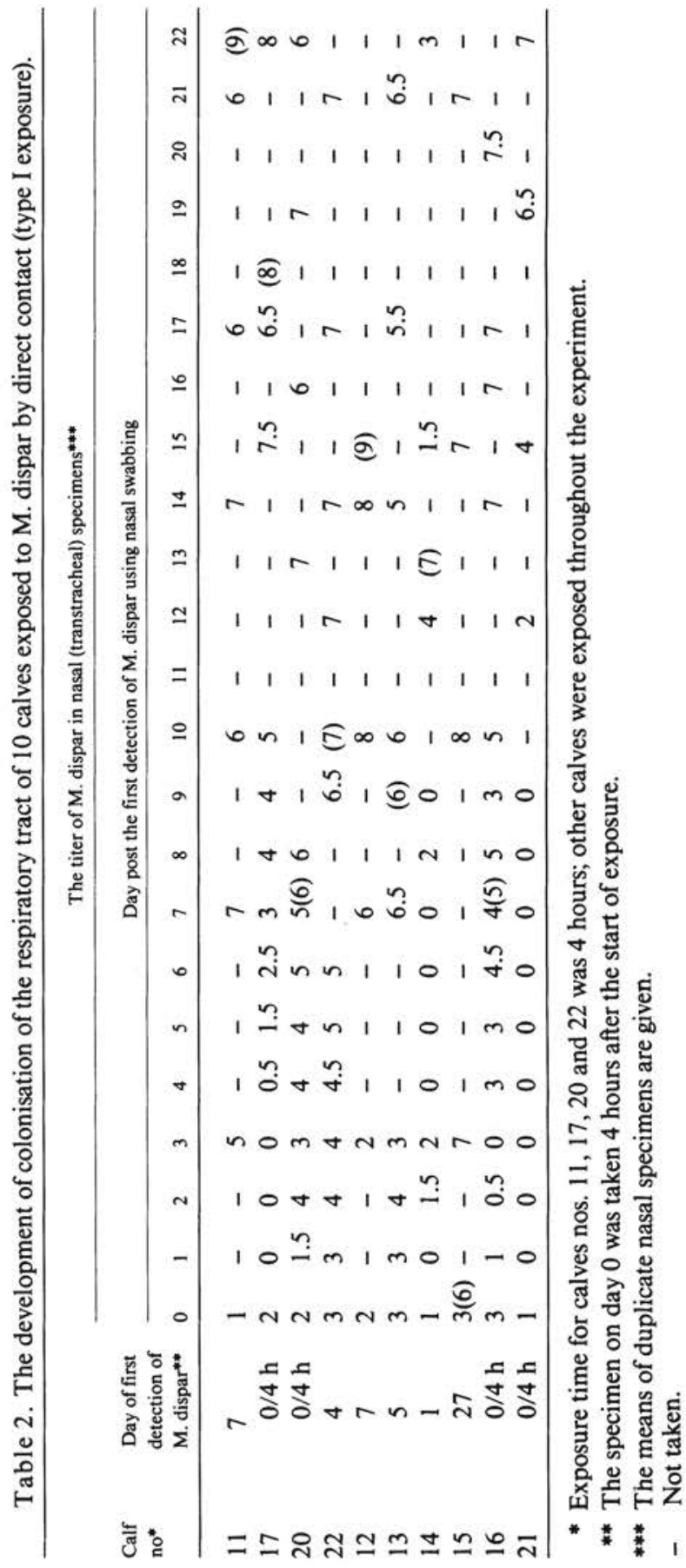

Acta vet. scand. vol. 28 no. 2 - 1987 
Table 3. Exposure of 4 susceptible calves to calves infected by M. dispar; distance $0.8 \mathrm{~m}$ to the nearest infected calf.

\begin{tabular}{|c|c|c|c|c|c|c|c|}
\hline \multirow{2}{*}{\multicolumn{2}{|c|}{ Susceptible calf }} & \multicolumn{5}{|c|}{ Conditions of exposure } & \multirow[b]{3}{*}{$\begin{array}{l}\text { Day of the first positive } \\
\text { (and the last negative) } \\
\text { nasal specimen from the } \\
\text { exposed calfe* }\end{array}$} \\
\hline & & & & Infected ca & & & \\
\hline \multirow[t]{3}{*}{ No } & $\begin{array}{l}\text { Age at the } \\
\text { start of the } \\
\text { exposure } \\
\text { (days) }\end{array}$ & No & $\begin{array}{l}\text { Posi- } \\
\text { tion* }\end{array}$ & $\begin{array}{l}\text { Mean titer (S.D.) } \\
\text { for M. dispar } \\
\text { during the } \\
\text { exposure }\end{array}$ & $\begin{array}{l}\text { Days infected } \\
\text { before the } \\
\text { experiment }\end{array}$ & $\begin{array}{l}\text { Clinical } \\
\text { signs"* }\end{array}$ & \\
\hline & & 3 & $2 \mathrm{~b}$ & $6.8(0.8)$ & 24 & & \\
\hline & & 128 & $3 b$ & $4.0(0.0)$ & 148 & - & \\
\hline \multirow[t]{5}{*}{4} & 10 & 2 & $4 b$ & $6.5(0.7)$ & 42 & - & $8(2)$ \\
\hline & & 1 & $4 b$ & $2.5(0.7)$ & 94 & - & \\
\hline & & 129 & $5 b$ & $0.0(0.0)$ & 148 & - & \\
\hline & & 4 & $2 \mathrm{~b}$ & $6.0(0.0)$ & $6-$ & & \\
\hline & & 129 & $3 b$ & $2.0(2.8)$ & 162 & + & \\
\hline \multirow[t]{6}{*}{5} & 24 & 3 & $4 b$ & $7.0(0.0)$ & 38 & - & $9(7)$ \\
\hline & & 2 & $4 b$ & $7.0(0.0)$ & 56 & - & \\
\hline & & 1 & $4 b$ & $1.0(0.0)$ & 108 & - & \\
\hline & & 128 & $5 b$ & $2.0(2.8)$ & 162 & - & \\
\hline & & 5 & $2 a$ & $3.5(2.1)$ & 28 & + & \\
\hline & & 3 & $3 a$ & $6.0(0.0)$ & 75 & - & \\
\hline \multirow[t]{5}{*}{6} & 27 & 2 & $3 a$ & $6.5(0.7)$ & 93 & - & $9(9)$ \\
\hline & & 4 & $4 a$ & $6.0(0.0)$ & 43 & + & \\
\hline & & 1 & $5 \mathrm{a}$ & $2.5(0.7)$ & 145 & - & \\
\hline & & 6 & $2 b$ & $7.0(0.0)$ & 19 & - & \\
\hline & & 4 & $3 b$ & $6.0(0.0)$ & 71 & + & \\
\hline \multirow[t]{4}{*}{7} & 81 & 3 & $4 b$ & $6.0(0.0)$ & 103 & - & $7(6)$ \\
\hline & & 2 & $4 b$ & $7.0(0.0)$ & 121 & - & \\
\hline & & 1 & $4 b$ & $2.0(0.0)$ & 173 & - & \\
\hline & & 5 & $5 \mathrm{~b}$ & $6.5(0.7)$ & 56 & + & \\
\hline
\end{tabular}

* The infected calf stayed at a disease of $0.8 \mathrm{~m}(2 \mathrm{a}$ and $2 \mathrm{~b})$ or further $(3-5)$ from the susceptible one (see Fig. 1 and 2).

** Clinical signs are coded as in Table 1.

**** The mean titers for M. dispar in first positive nasal specimens in calves nos. 4-7 were 3, 2, 2 and 1, respectively.

arance of $\mathrm{M}$. dispar was recorded. As can be seen from Fig. 3, the medians of the time elapsed until first detection of the infection in the 3 exposure groups were $4.5,8.5$ and 17 days, respectively. (Only the 5 succesfully exposed calves in group III are included). Differences between the groups were signif- icant $(\mathrm{p}<0.05$ ) when compared by the Kruskall-Wallis test (Siegel 1956). In pairwise comparison of the groups by using a post test only the difference between the groups I and III was significant $(\mathrm{p}<0.05)$. All the calves kept in the animal handling room of the isolation unit for a period of 
Table 4. Exposure of 9 susceptible calves to calves infected by M. dispar, minimum distance $1.3 \mathrm{~m}$ to the nearest infected calf.

\begin{tabular}{|c|c|c|c|c|c|c|c|}
\hline \multirow{2}{*}{\multicolumn{2}{|c|}{ Susceptible calf }} & \multicolumn{5}{|c|}{ Conditions of exposure } & \multirow[b]{3}{*}{$\begin{array}{l}\text { Day of the first positive } \\
\text { (and the last negative) } \\
\text { nasal specimen from the } \\
\text { exposed calf*** }\end{array}$} \\
\hline & & \multicolumn{5}{|c|}{ Infected calves } & \\
\hline No & $\begin{array}{l}\text { Age at the } \\
\text { start of the } \\
\text { exposure } \\
\text { (days) }\end{array}$ & No & $\begin{array}{l}\text { Posi- } \\
\text { tion* }\end{array}$ & $\begin{array}{l}\text { Mean titer (S.D.) } \\
\text { for M. dispar } \\
\text { during the } \\
\text { exposure }\end{array}$ & $\begin{array}{l}\text { Days infected } \\
\text { before the } \\
\text { experiment }\end{array}$ & $\begin{array}{l}\text { Clinical } \\
\text { signs** }\end{array}$ & \\
\hline 1 & 30 & $\begin{array}{l}123 \\
124 \\
122 \\
128 \\
129\end{array}$ & $\begin{array}{l}3 a \\
4 a \\
3 a \\
5 a \\
5 a\end{array}$ & $\begin{array}{l}1.0(0.0) \\
1.5(0.7) \\
1.0(0.0) \\
2.0(2.8) \\
1.5(2.1)\end{array}$ & $\begin{array}{r}200 \\
200 \\
200 \\
23 \\
23\end{array}$ & $\begin{array}{l}+ \\
+ \\
- \\
- \\
-\end{array}$ & $-(23)$ \\
\hline 2 & 34 & $\begin{array}{r}1 \\
128 \\
129 \\
124 \\
123\end{array}$ & $\begin{array}{l}3 a \\
3 a \\
3 a \\
4 a \\
5 a\end{array}$ & $\begin{array}{l}6.5(0.7) \\
5.6(0.7) \\
3.6(0.5) \\
1.5(0.7) \\
0.5(0.7)\end{array}$ & $\begin{array}{r}11 \\
65 \\
65 \\
242 \\
242\end{array}$ & $\begin{array}{l}- \\
+ \\
+ \\
+ \\
+\end{array}$ & $-(22)$ \\
\hline 3 & 82 & $\begin{array}{r}2 \\
1 \\
128 \\
129 \\
124 \\
123\end{array}$ & $\begin{array}{l}3 \mathrm{a} \\
3 \mathrm{a} \\
3 \mathrm{a} \\
3 \mathrm{a} \\
4 \mathrm{a} \\
5 \mathrm{a}\end{array}$ & $\begin{array}{l}5.5(1.0) \\
5.0(1.4) \\
3.3(1.6) \\
1.7(1.5) \\
0.5(0.7) \\
0.5(0.7)\end{array}$ & $\begin{array}{r}1 \\
53 \\
107 \\
107 \\
284 \\
284\end{array}$ & $\begin{array}{l}- \\
- \\
+ \\
+ \\
- \\
-\end{array}$ & $-(13)$ \\
\hline 8 & 7 & $\begin{array}{l}6 \\
4 \\
7 \\
5\end{array}$ & $\begin{array}{l}3 b \\
4 b \\
4 b \\
5 b\end{array}$ & $\begin{array}{l}5.0(0.0) \\
5.0(0.0) \\
6.0(0.0) \\
7.0(1.4)\end{array}$ & $\begin{array}{r}68 \\
120 \\
42 \\
105\end{array}$ & $\begin{array}{l}- \\
- \\
+ \\
-\end{array}$ & $14(1)$ \\
\hline 9 & 130 & 145 & $3 \mathrm{~b}$ & $5.4(1.3)$ & 0 & + & $17(14)$ \\
\hline 10 & 14 & $\begin{array}{r}145 \\
9\end{array}$ & $\begin{array}{l}3 \mathrm{~b} \\
5 \mathrm{~b}\end{array}$ & $\begin{array}{l}4.8(1.2) \\
5.2(1.0)\end{array}$ & $\begin{array}{l}73 \\
56\end{array}$ & $\begin{array}{l}+ \\
-\end{array}$ & $32(28)$ \\
\hline 18 & 56 & $\begin{array}{l}15 \\
14 \\
12 \\
11\end{array}$ & $\begin{array}{l}3 b \\
3 b \\
4 b \\
4 b\end{array}$ & $\begin{array}{l}6.3(2.2) \\
2.5(1.0) \\
3.0(1.6) \\
3.3(0.5)\end{array}$ & $\begin{array}{r}0 \\
29 \\
80 \\
87\end{array}$ & $\begin{array}{l}- \\
+ \\
+ \\
-\end{array}$ & $19(14)$ \\
\hline 19 & 61 & $\begin{array}{l}12 \\
11 \\
15 \\
14\end{array}$ & $\begin{array}{l}3 b \\
3 b \\
4 b \\
4 b\end{array}$ & $\begin{array}{l}3.0(1.6) \\
3.3(0.5) \\
6.3(2.2) \\
2.5(1.0)\end{array}$ & $\begin{array}{r}77 \\
84 \\
0 \\
26\end{array}$ & $\begin{array}{l}+ \\
- \\
+\end{array}$ & $-(19)$ \\
\hline 23 & 32 & $\begin{array}{l}21 \\
13 \\
20\end{array}$ & $\begin{array}{l}3 b \\
4 b \\
5 b\end{array}$ & $\begin{array}{l}7.0(0.0) \\
5.0(0.0) \\
5.5(0.0)\end{array}$ & $\begin{array}{r}15 \\
231 \\
104\end{array}$ & $\begin{array}{l}- \\
- \\
+\end{array}$ & $6(2)$ \\
\hline
\end{tabular}

* The infected calf stayed at a distance of $1.3 \mathrm{~m}$ ( $3 \mathrm{a}$ and $\mathrm{b}$ ) or further (4 and 5) from the susceptible one (see Fig. 1 and 2).

** Clinical signs are coded as in Table 1.

*** The mean titers for M. dispar on the day of first detection in calves nos. 8, 9, 10, 18 and 23 were 4, 1, 7,2 , and 3.5 , respectively; $-=$ No M. dispar isolation in the course of exposure. 


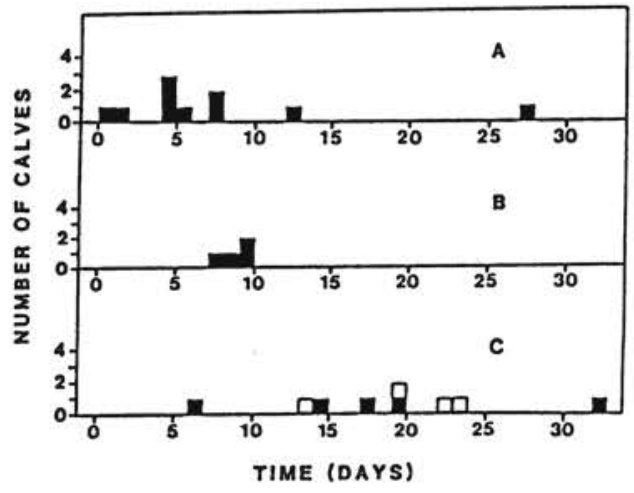

Figure 3. Distribution of first defection of M. dispar infection (घ) in the exposed calves or of their remaining uninfected $(\square)$ at the end of the experiment as tested by nasal swabbing. Types of exposure: A, direct contact (type I); B, exposed at a distance of $0.8 \mathrm{~m}$ (type II) or C, at a distance of $1.3 \mathrm{~m}$ (type III) with respect to the nearest infected calf.

Note. In the results for calves nos. 17, 16 and 21 the dates given are those for the start of a rising titer development (days 4,4 , and 12 , respectively), and not those for the transient positivity of the specimens at hour 4 (see Table 1).

approximately 2 weeks before the subsequent exposure in the animal-room remained negative for $\mathbf{M}$. dispar throughout this initial test.

With the exception of calf no. 14, whose nasal titers remained at a low level throughout the study period (see Table 4), the titers in all susceptible calves gradually increased to the level of $10^{5} \mathrm{ccu}$ or higher; in most of the cases the increase of titers took place within a period of 1 week after the first positive specimen of the ensuing rise. Of the calves exposed through direct contact (Table 4) for only $4 \mathrm{~h}$ the sharpest rise in titers took place in calf no. 20, whereas in the other 3 calves the level of $10^{5} \mathrm{ccu}$ was reached only a few days later. The pattern of increase in titer levels of calves nos. 1 to 8 has been described previously (Tanskanen 1983); the other 5 calves similarly exposed at distances of 0.8 or $1.3 \mathrm{~m}$ to the source of infection exhibited comparable patterns of rise. Transtracheal aspiration specimens taken in the early phase of the colonisation, detectable by nasal testing, were regularly positive and titers were usually higher than those in the nasal specimens taken simultaneously (Table 4). Interestingly, the transtracheal aspiration specimen from calf. no. 14 on day 14 showed a titer of $10^{7} \mathrm{ccu}$ while the nasal titer remained on a much lower level.

Among the 11 calves acting as source of infection in the latter part of the experiments (nos. 9, 145, 13, 15-17, 20 and 21; calf no. 14 excluded) the mean monthly nasal titers for the age group of $<1,1,2$ and 3 months were: $3.9 \times 10^{5}$ (S.D. $\left.9.3 \times 10^{1}\right), 2.5 \times 10^{6}$ $\left(2.2 \times 10^{1}\right), 1.3 \times 10^{5}\left(2.3 \times 10^{1}\right)$, and $1.4 \times$ $10^{4}\left(1.3 \times 10^{2}\right) \mathrm{ccu}$, respectively. The results suggest that neither the clinical state of the source calves, nor the level of M. dispar colonisation in these calves were confounding factors concerning the transmission time difference between the exposure groups.

\section{Discussion}

The general and relatively high sensitivity of the method of nasal swabbing for detection of M. dispar colonisation is additionally confirmed by the results of the present study. The results, however, also allow the inference that in the early phase of colonisation the infection has a latent period of varying length, as regards detectability by nasal swabbing. Consequently, when, for comparative purposes, the period preceding the first detection of the clearly established colonisation by $\mathrm{M}$. dispar is used as an estimate of transmission time, it must be reminded that this measure is only a relative one and also includes the latent period. The host dependent variability of the latent period (to 
be discussed below) is assumed to be roughly similar among the study groups and thus not to bias the comparative estimation of transmission times. Also, the combined measure used is, as such, practically relevant because the effect of management factors on the time of appearance of a clearly established colonisation is of interest. In the present context it must be mentioned that as to the sensitivity of nasal swabbing and pattern of M. dispar colonisation the results of Ribeiro (1979) on the experimental M. dispar infection following endobronchial inoculation are widely divergent from the present results. In Ribei$r o$ 's work M. dispar was only occasionally isolated from nasal mucosa of inoculated calves and even then usually in low titers.

In 4 of the 7 calves exposed through direct contact and sampled for the first time as early as $4 \mathrm{~h}$ after the start of exposure, these early nasal specimens showed low titers for M. dispar. A multiplication of the agent to the magnitude detected could not have taken place in the respiratory tract of a susceptible calf in the course of a few hours; therefore the bulk of the isolated population of $\mathrm{M}$. dispar must have been transferred from the infected calves acting as the source of infection. Though this early detection of the agent clearly demonstrated a transfer of the agent from the source to the susceptible contact this cannot, however, be considered as a sign of an inevitable initiation of the colonisation in the susceptible calf. In two cases these early appearances were followed by a short period of negativity for nasal detection. This may imply that even though the transfer of the agent occurred is was such a low level that infection was not induced. A more probable explanation, however, would be the failure to isolate organisms either due to the partial death of organisms or the disappearance of the agent to less accessible sites of the respiratory tract. In calf no. 21 the alternative that the early dose of infecting agent observed was totally destroyed in the airways of the susceptible calf seems quite possible. The findings thus clearly demonstrated the detectability of a dose of M. dispar transferred in conditions of close contact. They also suggest that the optimal conditions allowing such a sizeable and detectable transfer to occur are manifested when the susceptible and the infected calves have recently been brought together, and also that imposing a distance between the calves definitely diminishes the chances of such a detectable transfer. Because a recently received, detectable dose of $\mathrm{M}$. dispar may not necessarily, as indicated above, signify the start of an active colonisation and because the phenomenon of such a transfer seems to be limited to conditions of close physical contact, the validity and comparability and the measurements in the present study required that only positive specimens followed by a rise in titers were accepted as appropriate evidence for the establishment of infection.

The results suggest a lengthening of transmission time even with rather small increases in the distance between susceptibles and sources of infection. Some variation occurred, however, within all 3 groups. This could have been due to factors such as the density of infective mycoplasma particles on the nasal surfaces of infected calves and the extent of coughing and sneezing by them, both of which influence the numbers of M. dispar transferred. Differences between the study groups in regard to these properties were not obvious and are thus not thought to have biased the results and the comparison. Evidence is further provided by the results that susceptibility differences have had a definite bearance on the variation observed. The most important determinants of response to $\mathrm{M}$. dispar transferred 
to susceptible calves seem to be the size of the infectious dose and the rate of the initial development of colonisation (influencing the duration of latency). The variation of several days in the development of detectable colonisation among the 4 calves infected during a $4 \mathrm{~h}$ contact with the source of infection and also the wide variation in the development of such a colonisation among the other calves exposed through direct contact both appear more likely to reflect differences in the initial rate of colonisation than differences in the degree of exposure. As regards the distribution of calves into study groups according to the degree of susceptibility the allocation is judged to have taken place without having created any recognizable basis for bias.

Though most of the calves exposed through direct contact to the infected calves exhibited the initial point of a series of increasing nasal titers within a week, this applying also to those exposed only for $4 \mathrm{~h}$, two calves (nos. 15 and 2 - the latter at its second exposure), showed the start of this pattern of development of nasal titers only on days 27 and 19. Whether such a long latency could have occurred remains unknown but seems unlikely. The results of field studies (Tanskanen 1987b) lend no support to the hypothesis of the occurrence of such an extended phase of latency in the process of an early M. dispar colonisation. The delay in becoming effectively exposed appears to be a better explanation.

As regards the intensity of colonisation expressed by the titer levels reached and sustained and the rate of build-up of colonisation after first becoming detectable, no apparent difference was observed between the calves exposed by direct contact throughout the experiment and those withdrawn from the further exposure after $4 \mathrm{~h}$. Consequently, in this limited material the additional exposure after establishment of infection did not seem to have affected the course of events. For some other mycoplasma infections of the respiratory tract evidence has been presented or views put forward that repeated exposures may affect the overall process (Roberts 1974, Whittlestone 1976, Jemski et al. 1977). These reports have, however, primarily referred to pathological developments and not to the intensity of colonisation. A lack of direct correlation between these variables is acknowledged by Jemski et al. (1977). The relatively low pathogenicity, as well as good measurability, of $\mathbf{M}$. dispar infection thus seem to offer a "reduced model", limited largely to basic events concerning the multiplication and spread of the mycoplasmas in the respiratory tract, which does not cover the phenomena of indirect, and possibly confounding, pathological effects.

It seems, judging by the criteria given above, that not even the size of the naturally infecting dose, by implication highest among the calves in the group of closest exposure, appeared to affect the resulting intensity of colonisation by $\mathrm{M}$. dispar. In principal similar results regarding experimental M. pneumoniae infection in hamsters have been reported in Jemski et al. (1977). Interestingly, although the intensity of colonisation in the lungs of hamsters was not dose-dependent, the pathological effects were.

With regards to the ambient conditions, the humidity present in the experimental facilities in the present study was probably not optimal for the survival of mycoplasma in the air. The survival properties of M. dispar in different ambient conditions have not been investigated, but results on that subject concerning other Mycoplasma species (Wright et al. 1968 a, b) suggest that the midrange relative humidity prevailing in the facilities could have impaired the survival of 
M. dispar in the air. The survival of airborne M. pneumoniae, for instance, was found by Wright et al. (1968 b) to be increased in low and high humidities in comparison to a midrange humidity of $30-60 \%$.

The delay in the transmission observed in the conditions of separation of even a short air-space indicates that the droplets and not the droplet nuclei are the main mode of transmission of this infection. In this respect the present results are in accordance with the results concerning the transmission of other mycoplasma species (Steinberg et al. 1969, Bell \& Wheeler 1970, Whittlestone 1976, Kleven 1981). This comparison, however, also suggests that M. dispar probably is of higher transmissibility and, correlatively perhaps, shows higher levels of nasal titers than the other respiratory mycoplasmas referred to. For additional support to this view one can compare the present results with those by Goodwin (1972). The transmission of M. dispar among the animals at a close contact for only a relatively short time suggests that also in such a practical situation as transportation of calves the spread of this infection is quite likely to take place.

\section{Acknowledgements}

This study received financial support from The Research Council for Medical Sciences of the Academy of Finland and The Finnish Veterinary Science Foundation.

\section{References}

Bell DP, Wheeler SM: Susceptibility of caesarianderived rats to natural infection with chronic respiratory disease. Lab. Anim. 1970, 4, 4553.

Bitsch $V$, Friis $N F$, Krogh $H V$ : A microbiological study of pneumonic calf lungs. Acta vet. scand. 1976, 17, 32-42.

Brownlie J, Howard CJ, Gourlay RN: Pathogenicity of certain mycoplasma species in the bovine mammary gland. Res. Vet. Sci. 1976, 20 , 261-266.
Goodwin RFW: Isolation of Mycoplasma suipneumoniae from the nasal cavities and lungs of pigs affected with enzootic pneumonia or exposed to this infection. Res. Vet. Sci. 1972, 13, 262-267.

Gourlay RN, Leach RH: A new mycoplasma species isolated from pneumonic lungs of calves (Mycoplasma dispar sp. nov.). J. med. Microbiol. 1970, 3, 111-123.

Gourlay RN, Mackenzie A, Cooper JE: Studies of the microbiology and pathology of pneumonic lungs of calves. J. comp. Path. 1970, 80, 575-584.

Gourlay RN, Howard CJ, Thomas LH, Wyld SG: Pathogenicity of some Mycoplasma and Acholeplasma species in the lungs of gnotobiotic calves. Res. Vet. Sci. 1979, 27, 233-237.

Howard CJ, Gourlay RN, Thomas LH, Scott EJ: Induction of pneumonia in gnotobiotic calves following inoculation of Mycoplasma dispar and ureaplasmas (T-mycoplasmas). Res. Vet. Sci. 1976, 21, 227-231.

Jemski JV, Hetsko CM, Helms CM, Grizzard $M B$, Walker JS, Chanock RM: Immunoprophylaxis of experimental Mycoplasma pneumoniae disease: Effect of aerosol particle size and site of deposition of M. pneumoniae on the pattern of respiratory infection, disease, and immunity in hamsters. Infect. Immun. 1977, 16, 93-98.

Kleven SH: Transmissibility of the F strain of Mycoplasma gallisepticum in Leghorn chickens. Avian Dis. 1981, 25, 1005-1018.

Muenster OA, Ose EE, Matsouka T: The incidence of Mycoplasma dispar, Ureaplasma and coventional Mycoplasma in the pneumonic calf lung. Canad. J. comp. Med. 1979, 43, 392 $-398$.

Ribeiro OC: Experimental infection of calves with Mycoplasma dispar. Ph.D. Thesis. Iowa State University, Ames, 1979.

Roberts DH: Experimental infection of pigs with Mycoplasma hyopneumoniae (suipneumoniae). Brit. vet. J. 1974, 130, 68-74.

Rosendal $S$, Martin $S W$ : The association between serological evidence of mycoplasma infection and respiratory disease in feedlot calves. Canad. J. vet. Res. 1986, 50, 179-183. 
Siegel S: Nonparametric Statistics for the Behavioral Sciences. McGraw-Hill Book Company, New York 1956.

Steinberg $P$, White RJ, Fuld SL, Gutekunst RR, Chanock RM, Senterfit LB: Ecology of Mycoplasma pneumoniae infections in Marine recruits at Parris Island, South Carolina. Amer. J. Epidemiol. 1969, 89, 62-73.

Tanskanen $R$ : Longstanding colonisation of the respiratory tract of calves by Mycoplasma dispar. Acta vet. scand. 1983, 24, 334-336.

Tanskanen $R$ : Colonisation pattern of the respiratory tract of calves by Mycolasma dispar. Acta vet. scand. 1984, 25, 577-592.

Tanskanen $R$ : The prevalence and level of colonisation by Mycoplasma dispar and other mycoplasmas on calf rearing farms. Acta vet. scand. 1987a, 28, 209-226.

Tanskanen $R$ : Transmission of Mycoplasma dispar among a succession of newborn calves on a dairy farm. Acta vet. scand. 1987b, 28, in press.

Thomas LH, Smith GS: Distribution of mycoplasmas in the nonpneumonic bovine respiratory tract. J. comp. Path. 1972, 82, 1-4.

Thomas LH, Howard CJ: Effect of Mycoplasma dispar, Mycoplasma bovirhinis, Acholeplasma laidlawii and $\mathrm{T}$-mycoplasmas on explant cultures of bovine trachea. J. comp. Path. 1974, 84, 193-201.

Whittlestone P: Effect of climatic conditions on enzootic pneumonia of pigs. Int. J. Biometeor. 1976, 20, 42-48.

Wright DN, Bailey GD, Hatch MT: Survival of airborne mycoplasma as affected by relative humidity. J. Bact. 1968a, 95, 251-252.

Wright DN, Bailey GD, Hatch MT: Role of relative humidity in the survival of airborne Mycoplasma pneumoniae. J. Bact. 1968b, 96, 970-974.

\section{Sammendrag \\ Mycoplasma dispars smittbarhet under experimentella förhållanden.}

Tjugotre 1- til 18-veckor gamla Ayrshire kalvar utsattes för infektion med Mycoplasma dispar en eller två åt gången $i$ en serie av på varandra följande experiment. Djuren utsattes för smittan antingen genom direkt kontakt d.v.s. möjlighet till fysisk kontakt mellan mottagliga och infekterade kalvar (typ I) eller genom separering av mottagliga djur från det närmaste infekterade med ett avstånd på $0.8 \mathrm{~m}$ (typ II) eller $1.3 \mathrm{~m}$ (typ III). För att påvisa infektion och för att mäta kolonisationsnivån togs talrika nässekretsprov.

Tio, 4 , och 9 kalvar utsattes för typ I, II, och III smitta i nämd ordning. Om det första provet som föregick en höjning av titern $\mathrm{i}$ de påföljande proven användes som ett tecken på att infektionen etablerat sig i en mottaglig kalv är medianerna (variationsvidderna) av tiderna för infektionens utbredning (inklusive latensperioden för den tidiga kolonisationen som inte kan påvisas genom nässekretprov) i de 3 utsatta grupperna: 4.5 (1-27), 8.5 (7-9) och 17 (6-32) i nämnd ordning. Skillnaden mellan grupperna I och III är signifikant ( $P$ $<0.05$ ). De sista värden för typ III:s experiment motsvarar endast 5 kalvars framgångsrika medsmittning; de återstående 4 kalvarna av $9 \mathrm{i}$ denna experimentgrupp förvärvade inte infektionen inom 2 eller 3 veckors perioderna som försöket pågick. Resultaten motsvarar en smittoväg via droppar.

Fyra kalvar som utsattes för smitta under 4 timmars tid genom direkt kontakt visade sig vara infekterade på dagarna $0,4,4$, och 7 . En variabilitet av latensperioden, med referens till nässekretprov, var häntydd.

Proven tagna på timme 4 av fyra av de 7 kalvarna inom experiment $\mathrm{I}$ hade låga titrar för $\mathrm{M}$. dispar. Endast hos en av dessa kalvar åtföljdes denna upptäckt av tidig mykoplasma överföring av en positivitet och av en höjning av titrarna bland de följande proven. De övriga 3 kalvarna blev positiva på nytt, med senare utveckling av kolonisation, först på dagarna 4,4 , och 12 .

(Received January 30, 1987).

Reprints may be requested from: Raili Tanskanen, Department of Microbiology and Epizootology, College of Veterinary Medicine, P. O. Box 6, SF-00551 Helsinki 55, Finland. 